\title{
Comportamentos Lúdicos entre Crianças do Nordeste do Brasil: Categorização de Brincadeiras ${ }^{1}$
}

\author{
Ana Karina Santos ${ }^{2}$ \\ Álvaro Machado Dias \\ Universidade de São Paulo
}

\begin{abstract}
RESUMO - Este artigo visa categorizar as brincadeiras das crianças de um povoado rural do nordeste do Brasil. Foram observadas individualmente 32 crianças entre dois e 12 anos, de ambos os sexos, brincando em ambiente livre, em sessões de cinco minutos. A categoria de ‘brincadeiras simbólicas' foi a mais observada (49\%). Os temas das brincadeiras simbólicas estavam predominantemente atrelados ao modo de vida local. Diferenças de gênero foram observadas e analisadas. Os dados sugerem que meninas brincam mais simbolicamente, enquanto as brincadeiras dos meninos são mais variadas. A relação entre brincadeira e contexto baseia-se no aproveitamento das potencialidades que o ambiente oferece para o desenvolvimento da criança caracterizando as relações entre aspectos particulares de cada ambiente e as atividades lúdicas desenvolvidas.
\end{abstract}

Palavras-chave: Brincadeiras; Desenvolvimento Infantil; Desenvolvimento Social; Comunidade Rural.

\section{Ludic Behavior among Children of Brazil's Northeast Region: Categorization of Playful Activities}

\begin{abstract}
This paper aims to categorize the most frequent playful activities in a sample of children from a rural community of Brazil's northeast region. Thirty two children of both sexes, aged 2-12 years, were individually observed during free play, in five minutes sessions each. The most observed category of play was 'symbolic games' (49\%). The themes of the symbolic games were predominantly tied with the local way of living. Gender differences were observed and analyzed. The collected data suggest that female plays tend to be symbolic, while male plays tend to be more varied. It was observed that the relation between playful activities and local context is based upon the employment of resources that the specific environment offers to the child's development, characterizing the relations between particular contexts and the ludic activities developed in it.
\end{abstract}

Keywords: Play; Child Development; Social Development; Rural Community

Desde que as atividades lúdicas adquiriram o status de tópico de interesse primordial entre etólogos e psicólogos do desenvolvimento, os estudos científicos ganharam fôlego, promovendo o surgimento de perspectivas que aprofundam o entendimento das formas elementares de funcionamento da mente infantil (Power, 2000). Atualmente faz-se amplamente aceito que a forma espontânea de se expressar através da brincadeira é um importante elemento para estudos comparativos entre espécies animais e entre culturas humanas (Bekoff \& Byers, 1998; Brougère, 1998).

Não obstante, apesar da grande quantidade de pesquisas atualmente disponíveis sobre o brincar, questões importantes associadas a este comportamento não estão claras, a exemplo da sua função no desenvolvimento infantil - aspecto este que intriga estudiosos do comportamento humano. A este respeito, a concepção de que a brincadeira serve para treinar habilidades que serão úteis no futuro é a que mais predomina

1 Agradecimento: à Profa. Dra. Ilka Dias Bicharas (UFBA) pela orientação de mestrado, a qual resultou na pesquisa apresentada neste artigo. Apoio: Capes.

2 Endereço para correspondência: Universidade de São Paulo, Departamento de Psicologia Experimental, Laboratório de Psicologia Comparativa e Etologia. Setor: Interação Social e Ontogênese. Av. Prof. Mello Moraes, 1721. Butantan Cidade Universitária, São Paulo, SP. CEP 05508-030 Tel: 11 3091-4448, ramal 35.E-mail: anaks@usp. br; alvaromd@usp.br e influencia até hoje as teorias sobre o comportamento lúdico, incluindo autores emblemáticos da Psicologia do Desenvolvimento como Piaget e Vygotsky.

Piaget (1971) considerava que, além de refletir o nível de desenvolvimento cognitivo da criança por meio dos processos de assimilação e acomodação, brincar teria como principal vantagem consolidar e pôr em prática comportamentos, conceitos e habilidades previamente aprendidas; ou seja, dir-se-ia que ao brincar, a criança executa e consolida habilidades recentemente adquiridas.

Ao contrário de Piaget (1971), Vygotsky (2000) concebia a brincadeira como um revelador em potencial de novas habilidades que seriam realizadas em situações futuras. Vygotsky definia a brincadeira como criadora de uma zona de desenvolvimento proximal, isto é, como geradora de um ambiente subjetivo para a expansão das capacidades pessoais (desde esforços factíveis), facilitando o alcance de um estágio de controle e maestria plenos sobre as mesmas. Isso ocorria fundamentalmente porque no brinquedo a criança tende a agir como se fosse mais velha do que realmente é. Para ele "no brinquedo a criança se comporta, além do seu comportamento diário; no brinquedo, é como se ela fosse maior do que é na realidade" (Vygotsky, 2000; p.17).

Vygotsky (2000) explicita o significado da mudança que ocorre no desenvolvimento do próprio brinquedo e as transformações internas no desenvolvimento da criança que 
surgem em sua conseqüência. Ele considerava a atividade lúdica decisiva tanto para o desenvolvimento emocional e social da criança quanto para o desenvolvimento cognitivo, pois promove o pensamento abstrato, a aprendizagem e o desenvolvimento da linguagem, a interação com os outros e o autocontrole.

No entanto, atualmente vêm surgindo novas concepções acerca da imaturidade infantil que vão além das discussões baseadas num caráter teleológico do brincar. Entre estas, a mais divulgada atualmente é a de Bjorklund (1997) que sugere que alguns comportamentos da infância não são preparação para a vida adulta, tendo sido delineados para adaptar a criança a seu ambiente presente e específico, indicando que a brincadeira teria sido selecionada pelo valor imediato de sobrevivência. Em linha com esta perspectiva, Pellegrini e Smith (1998) vêem a brincadeira como um ajustamento específico ao contexto da imaturidade infantil, consistente com a idéia de que aspectos da infância são adaptativos apenas para aquele momento do desenvolvimento, sendo a natureza e o tempo dos benefícios variantes em função da espécie e do ambiente (Burghardt, 1999; Spinka, Newberry \& Bekoff, 2001).

$\mathrm{Na}$ concepção de benefícios imediatos da brincadeira podemos afirmar que estão voltados para o acoplamento ao ambiente, no sentido de uma maximização do aproveitamento das potencialidades e aptidões, em função de uma compensação de seus aspectos ambientais pouco favoráveis à otimização desenvolvimental infantil. Na perspectiva de longo prazo, a brincadeira prioriza o treino de habilidades importantes para a vida em cada ambiente, refletindo-se no tipo e conteúdo das brincadeiras predominantes.

Numa abordagem ainda mais recente, Ribeiro, Bussab e Otta (2005) propõem que a brincadeira evoluiu como prática marcante na infância humana graças às interações criança-criança que ela proporciona. Este agrupamento de crianças viabilizou o autocuidado, que não se refere a um cuidado explícito, manifestado em práticas de maternagem, mas a um 'estar junto'. O potencial adaptativo reside na diminuição do tempo de maternagem e de supervisão das crianças pelos adultos, permitindo assim que esses pudessem se dedicar a outras atividades importantes (aumento da aptidão inclusiva). Nessa visão, o autocuidado seria uma função essencial da brincadeira, e estes - o autocuidado e o brincar - por sua vez, funções da infância.

Estudos observacionais da brincadeira no modo de vida tribal, semelhante ao caçador coletor que caracterizou mais de $95 \%$ da evolução humana (Buss, 2005) e que pode ser considerado nosso ambiente natural, ajudam na compreensão da função da brincadeira. Por exemplo, estudos feitos por Gosso (2005) entre os índios Parakanã, mostraram que as crianças passam praticamente todo o dia brincando em grupo, longe da supervisão direta dos adultos. O grupo é composto por crianças mais velhas e menores, que cuidam umas das outras, brincando no interior da floresta amazônica, incluindo um rio de correnteza: não se verificaram, ao longo dos nove meses de observação, acidentes graves.

Brincar é um comportamento universal, sendo característica intrínseca do repertório mamífero (Fagen, 1981), em relação ao qual há registros representativos da relevância desta categoria de atividade mesmo em sociedades antigas como a Hindu (cerca de 2500-1700 a.C.) (Oke, Khattar, Pant \& Saraswathi, 1999).

Segundo Huizinga (1971/2000) a brincadeira é mais antiga que a cultura humana e não passou por amplas modificações ao longo do processo de sucessão das muitas civilizações, sendo considerada, por esta razão, um grande arquétipo das atividades da sociedade humana. Alternativamente, é de se aventar que este sistema de comportamentos de fato se altere em conjunção com práticas sociais. Por exemplo, atualmente, faz-se notável a existência de maciços investimentos sociais em vicissitudes relacionadas à prática do brincar, como a construção de espaços públicos de brincadeira, playgrounds, brinquedotecas, brinquedos e jogos que incluem recentes avanços tecnológicos, como videogames e computadores (Bichara, 1994). É precisamente nessa seara que se verte o presente artigo, sob o mote de que as alterações do ambiente sócio-cultural brasileiro, mediadas pela crescente urbanização e avanço tecnológico, possam estar alterando o modo tradicional de brincar, o qual merece assim um estudo catalográfico.

\section{O que é e como identificar a brincadeira}

Faz-se consensual entre os estudiosos do brincar que este é um comportamento fácil de ser reconhecido, mas difícil de ser definido. Como afirma Bjorklund (2002), a brincadeira é como a arte: nós a reconhecemos quando a vemos, mas não sabemos como definí-la. Não há uma definição única que satisfaça a todas as acepções implicadas em todas as correntes metodológicas que se vertem sobre o tema, assim como não há concordância entre os estudiosos sobre suas origens e sua função ${ }^{3}$.

Apesar da dificuldade de definição, há características envolvidas na brincadeira que aparecem na maior parte das definições propostas (Sutton-Smith, 1986). Entre elas destaca-se o alto nível de atividade (Smith, Cowie \& Blades, 1998; Yamamoto \& Carvalho, 2002) e a adoção de padrões comportamentais usados em contextos funcionais reais, mas desvinculados de sua motivação original e a presença de movimentos exagerados e repetitivos. ${ }^{4}$

Talvez o critério de maior concordância para definir a brincadeira é que esta parece não servir para nenhum propósito imediato (Bjorklund, 2002); neste sentido podemos afirmar que, na brincadeira, os meios justificam os fins, postulação amplamente aceita, sobretudo sob o enfoque etológico. É a partir desta falta de propósitos que ocorre na brincadeira o self-handicap, isto é, dinâmica lúdica através da qual os mais fortes ou mais experientes se colocam em desvantagem em relação aos mais fracos e mais jovens (Spinka, Newberry \& Bekoff, 2001).

Contrapondo-se à dificuldade de definição, está a facilidade de ser reconhecida a partir dos chamados "sinais de brincadeira": em macacos, por exemplo, esses sinais estariam na face, com boca aberta, similar ao que acontece com crianças em brincadeiras turbulentas onde a face de brincadeira, sorridente, serve para diferenciar o brincar de brigar de

\footnotetext{
3 Para uma discussão ver Burghardt (1999) e Pellegrini e Smith (1998).

4 Para uma introdução ver Fagen (1981).
} 
brigas de verdade (Smith, Cowie \& Blades, 1998), aliados à ausência de características que nos permitam asseverar que o limite do brincar foi rompido e que, por extensão, o conceito já não mais se aplica: componentes de ataque ou medo estão ausentes, assim como ferimentos ou outros efeitos de lutas verdadeiras (Meaney, Stwart \& Beatty, 1985).

O reconhecimento de interações lúdicas entre animais se dá em resposta ao relaxamento aparente e à ausência de motivações sexuais ou agressivas. Parece que o que conta não é tanto o padrão comportamental operante, em termos da obtenção da função basicamente associada ao padrão, mas o modo como os padrões são apresentados, ponto no qual os sinais de brincadeira operam (Ehrmann, Lewis \& Lewis, 1968).

Dado o fato de que seria especialmente arriscado para um animal interpretar erroneamente qualquer objetivo final de um comportamento, neste sentido, os sinais de brincadeira evoluíram no intuito de distinguir padrões comportamentais sérios daqueles não-sérios, favorecendo a emissão de uma resposta apropriada na situação (Bekoff \& Allen, 1998). Estando presente em inúmeras espécies, esses padrões de comportamento denotam a complexidade dos mecanismos subjacentes à realização bem sucedida dos comportamentos geneticamente facilitados.

Brincar é para valer e só pode ser compreendido em sua generalidade filogenética, em face das vantagens que implica àqueles que o praticam. Como bem definiu Eibl-Eibesfeldt (1989) animais que brincam são precisamente aqueles que devem adquirir muitas habilidades diferentes através da aprendizagem. Não é por coincidência que somos os que mais brincam e os mais inteligentes dos animais.

Partindo das especificidades humanas no campo da brincadeira chegamos ao seu aspecto mais controverso: o faz-de-conta. Tomasello e Call (1997) consideram que este tipo de brincadeira é específico dos humanos, caracterizando uma descontinuidade filogenética. Pellegrini e Bjorklund (2004) defendem que o faz-de-conta está presente também em primatas não humanos, com a diferença de que para estes a simbolização serve para benefícios imediatos, como adquirir habilidades sociais, principalmente através da troca de papéis, presente no self-handicap (Rosenberg, 1990). De fato, não podemos deixar de considerar que mesmo admitindo a existência da brincadeira simbólica entre primatas não humanos, esta é rudimentar quando comparada à complexidade presente no faz-de-conta infantil.

A comunicação em espécies não-verbais não envolve este dispositivo paradigmático do nosso entendimento de mundo e indexador de uma categoria fundamental de brincadeiras humanas: a possibilidade de tratar do que não necessariamente tem existência imanente, para o que o exercício da simulação, cujo apogeu lúdico se dá no faz de conta, é salutar. $\mathrm{O}$ ato de brincar nos permite enfrentar com naturalidade uma forma de relacionamento com o mundo que tem como contrapartida intelectual a possibilidade do sujeito intencional ser capaz de tratar a si mesmo como outrem.

Brincar de faz-de-conta requer a capacidade da metarepresentação, que envolve estar consciente de que estão fingindo algo e de que aquela situação projetada externamente é mentalmente representada. Neste sentido, quando a criança chega a este ponto no faz-de-conta ela também passa a per- ceber que a mente representa o mundo, fenômeno chamado de teoria da mente (Taylor \& Carlson, 1997).

Com base nestes aspectos, a brincadeira simbólica pode ser vista como um indicador do desenvolvimento cognitivo da criança (Piaget, 1971). Quando as crianças brincam de faz-de-conta, elas reconhecem que as pessoas individualmente representam o mundo mentalmente, capacidade que não é desenvolvida até cerca dos quatro anos de idade.

Não restam dúvidas de que o brincar de faz-de-conta é universal entre todas as sociedades humanas. No entanto, diversos estudos têm voltado atenção para as variações no lúdico simbólico, principalmente em termo de freqüência relativa em relação a outros tipos de brincadeiras, temas e enredos. Este foco específico da pesquisa sobre brincadeira emerge estimulado como contrapartida a alguns vieses afirmativos gerados por pesquisas pioneiras que afirmam que crianças pobres ou socialmente desvalorizadas seriam deficientes em vários aspectos, principalmente no que se refere ao uso da imaginação.

Durante certo tempo, vários pesquisadores afirmaram que as brincadeiras simbólicas dessas crianças eram menos freqüentes e de baixa qualidade. Esses trabalhos chegaram a incluir adjetivos como "repetitivas", "simplistas", "não-imaginativas", "dependentes de objetos" e "concretas" para caracterizá-las (Johnson, Christie \& Yawkey, 1999).

A natureza destas afirmações traz implícito outro debate, não menos controverso, que se relaciona a uma questão que até hoje permeia a pesquisa sobre desenvolvimento infantil e o pensamento da população em geral, e sobre a qual nos deteremos a seguir.

\section{Existe um ambiente de desenvolvimento ideal?}

Considerando que o processo desenvolvimental ocorre em reciprocidade com um contexto sócio-psicológico, determinadas vicissitudes deste processo não podem ser compreendidas em recortes que as alijem do mesmo (Seild de Moura, 2006).

Diversas abordagens teóricas discutem conceitualmente contexto. Para Göncün, Tuermer, Jain e Johnson (1999), estas perspectivas teóricas têm em comum a ênfase na importância das experiências sociais e culturais para modelar o pensamento e a interpretação de mundo das crianças, e uma mudança de foco da criança individual para a criança no contexto.

É provável que essa mudança seja um dos pontos de origem da noção presente no senso-comum e no meio acadêmico de que o desenvolvimento é mais favorável em alguns ambientes que em outros.

É a partir desse novo quadro de referência que o estudo da diversidade vem sendo reconhecido como necessário e indispensável para a produção de conhecimento no campo da psicologia do desenvolvimento. Farver (1999) chama atenção para um aspecto relevante e em voga nas pesquisas atuais na área: a importância de entender como o processo de desenvolvimento afetivo-cognitivo em uma cultura particular leva a diferentes resultados desenvolvimentais.

O desenvolvimento pauta-se por alguns determinantes universais, de base biológica, e outros, são construídos socialmente de acordo com cada época, lugar e cultura, 
como por exemplo, a realização profissional, independência, casamento etc. Assim, devemos reconhecer que não há um caminho único para o desenvolvimento.

Além disso, é necessário explorar e conhecer as potencialidades e limites de cada ambiente de desenvolvimento e suas implicações para a criança. Neste sentido, o comportamento de brincar, especificamente, recebe influência direta do ambiente e essa relação tem sido largamente explorada por estudiosos da área, revelando dados interessantes de cada realidade particular, a exemplo das pesquisas realizadas por autores como Gosso (2005) sobre a brincadeira das crianças indígenas Parakanã na Amazônia; Bichara (2001) que estudou o brincar das crianças indígenas Xocó e Mocambo, comunidade de descendentes de escravos do sertão de Sergipe; e Morais (2004) pesquisando as brincadeiras infantis de crianças de Ubatuba, no litoral paulista.

As crianças apresentam ou não certos tipos de brincadeira por causa das condições contextuais como o espaço físico e o tempo disponível para brincar e objetos para sustentar sua imaginação. As atitudes dos adultos em relação à brincadeira também são fator crítico. Se faltarem condições para a aprendizagem em um grupo sócio-cultural, essa deficiência vai se refletir na ausência de determinada brincadeira ou no seu subdesenvolvimento. Para Johnson, Christie e Yawkey (1999), fatores sociais e econômicos pesam mais que fatores culturais em contribuir para a freqüência e a qualidade da brincadeira. Assim, o conteúdo da brincadeira seria diferente por causa da cultura, mas o nível da brincadeira dentro de cada cultura varia em função do nível sócio-econômico.

Um exemplo disso é a pesquisa realizada por Smith e Dosdsworth (1978) sobre o faz-de-conta de pré-escolares de diferentes classes sociais na Inglaterra, demonstrando que crianças de classe média se engajavam em mais episódios de faz-de-conta com grandes elaborações, enquanto crianças mais pobres brincavam mais com objetos. Os autores relacionaram estes resultados a um atraso no aparecimento da brincadeira simbólica em crianças de nível sócio-econômico baixo e afirmam que parece ser de comum acordo entre os estudiosos, que este pode ser um fator decisivo se o aparecimento do faz-de-conta ocorrerá por volta dos três anos ou mais tarde.

Apesar da grande quantidade de pesquisas realizadas na área, a maioria dos estudos enfoca as crianças urbanas, geralmente brancas e de classe média (Göncün, Tuermer, Jain \& Johnson, 1999). A produção que trata de ambientes de desenvolvimentos específicos ainda é pequena, mesmo com o crescente interesse de pesquisadores pelas questões que cercam a relação contexto e desenvolvimento infantil.

Por muito tempo os estudos interculturais sobre o desenvolvimento infantil não abordavam as diferenças étnicas, sociais e culturais em relação ao modo de vida e cultura dessas sociedades. Muitos estudos comparativos ainda tomam as sociedades européias e americanas como referência.

É a partir desse quadro que as pesquisas regionais devem ser destacadas. Os trabalhos realizados em contextos específicos são importantes, teórico e metodologicamente, pelo seu papel no desenvolvimento de uma Psicologia comprometida com a realidade brasileira, focalizando diferentes grupos culturais e valorizando peculiaridades regionais e históricas. Neste sentido, a brincadeira funciona como porta privilegiada de acesso a diversos aspectos do desenvolvimento infantil e às práticas sociais e culturais de um grupo.

Dentro de uma tradição de pesquisa que tem entendido a importância da brincadeira e do contexto sócio-cultural-afetivo para o desenvolvimento das crianças, os estudos têm se baseado em comparações do desenvolvimento em sociedades urbanas mais típicas e em ambientes específicos como grupos indígenas e comunidade litorânea, todos eles focalizando ambientes nos quais as crianças podem se arranjar de forma espontânea para brincar (Bichara, 1999; Carvalho \& Pontes, 2003; Gosso, Otta, Moraes, Ribeiro \& Bussab, 2005).

Portanto, investigar comportamentos infantis em contextos específicos, mais particularmente as brincadeiras, constitui um promissor campo de pesquisas sobre a influência de variáveis sócio-culturais no desenvolvimento infantil, assim como a adaptabilidade da criança que brinca às condições encontradas, tais como: estar na rua, no mato, dentro de casa etc., ter ou não brinquedos, número de participantes, idade, sexo.

Partindo desta perspectiva, esta pesquisa teve como objetivo categorizar as brincadeiras das crianças de um povoado rural do agreste sergipano, estabelecendo sua relação com o contexto.

\section{Método}

\section{Participantes}

Foram observadas 32 crianças entre dois e doze anos, de ambos os sexos, brincando em ambiente livre de um povoado da cidade de Itabaiana, localizada no agreste sergipano. A escolha das crianças se deu com base nos critérios de idade e se freqüentavam a rua para brincar. Este último foi baseado nas observações prévias dos pesquisadores os quais identificavam as crianças e em seguida anotavam dias e horas nos quais as crianças saíam para brincar na rua.

Não houve contato entre os pesquisadores e as crianças. Os aspectos éticos que garantem a integridade das crianças foram considerados neste estudo. Foi garantido o sigilo da identidade e das informações obtidas.

\section{Local}

As crianças foram observadas nas áreas livres de um povoado localizado no agreste de Sergipe: povoado São Cristóvão, pertencente ao município de Itabaiana-SE, localizada na região agreste do estado, com população de 76.000 habitantes, clima de transição entre o semi-árido e o atlântico e distante 56 quilômetros da capital do estado, Aracaju. A economia local é baseada no comércio e no transporte de cargas. A população é de classe econômica baixa, os homens trabalham como caminhoneiros ou feirantes e as mulheres em geral são donas de casa. 


\section{Procedimento}

Os dados foram coletados através da observação direta de comportamento em ambiente natural, seguindo o método de observação do sujeito focal, elaborado por Altmann (1974).

O observador seguia as crianças mais de perto e registrava cursivamente os comportamentos que observava. O tempo de observação foi de cinco minutos por criança, escolhida aleatoriamente entre as participantes do estudo que estivesse brincando nas áreas livres do povoado como praça, rua e calçadas. Os registros cursivos consistiam em anotar de forma detalhada os comportamentos, de acordo com a seqüência temporal, permitindo também a descrição das circunstâncias ambientais nos quais os comportamentos ocorreram.

Foram obtidos 192 registros de cinco minutos, totalizando 960 minutos de observação. A maioria dos registros foi realizada no final da tarde, pois a temperatura está mais amena e as crianças saem de casa para brincar. As observações foram realizadas durante quatro meses, entre julho e outubro, num total de 24 visitas ao povoado.

A coleta de dados foi realizada seguindo-se os seguintes passos: os pesquisadores se aproximavam da praça e identificavam os participantes presentes. Em seguida, escolhia aleatoriamente uma criança e iniciava o registro. As crianças foram acompanhadas a uma distância de 10 a 50 metros, tendo apenas os seus comportamentos em atividade livre registrados, quando possível eram registradas também suas verbalizações.

Foi seguida uma folha de registro previamente elaborada para este estudo, na qual constaram dados como o número de participantes no grupo, atividades, objetos utilizados na brincadeira, condições climáticas, ambiente, local e hora.

Para identificar o brincar foram utilizados os critérios adotados por Bichara (1994) que se mostraram úteis no sentido de evidenciar se um determinado comportamento é uma brincadeira; a verbalização e o comportamento motor. O que a criança verbaliza nos indica não só se a criança está brincando, mas também do que brinca, pois é comum que, durante a atividade lúdica, ocorra a emissão de gritos, risos, mudança do tom de voz e negociação de papéis e enredos, além do estabelecimento de diálogos que são fortes indícios de que estão brincando. O segundo critério é o motor, evidenciado por movimentos e gestos.

Durante as observações, os pesquisadores procuraram atentar para os seguintes aspectos: 1) como a criança se dirigia ao local; 2) com quem estava; 3) idade; 4) regras explícitas e implícitas da brincadeira; 5) tipo de brincadeira; 6) temas da brincadeira e 7) forma de arranjo social dos participantes.

Para complementar as observações foram feitos contatos gerais com adultos sobretudo os pais destas crianças, objetivando obter informações sobre o modo de vida local e o hábito das crianças de brincar na rua.

\section{Análise dos dados}

As unidades de análise foram as brincadeiras das crianças. Os dados coletados foram classificados em categorias empíricas, a exemplo das contidas em pesquisas na área, que serão detalhadas adiante; em seguida, foi realizada análise da freqüência de cada categoria, considerando os dados brutos e os valores percentuais. Esta técnica foi utilizada no intuito de identificar quais eram as categorias de brincadeira mais freqüentes, e ainda a relação entre os tipos de brincadeira e as idades e o gênero das crianças.

\section{Categorização das brincadeiras}

Primeiramente foi adotada a classificação proposta por Moraes e Otta (2003) a partir das categorias encontradas em Parker (1984) e Piaget (1971) sobre os tipos de brincadeiras: 1 - Brincadeiras de contingência física/de exercício sensório motor: a criança exercita um conjunto de comportamentos, relações espaciais e causais e aprende a força e a função dos objetos manuseados; 2 - Brincadeiras de contingência social: envolvem revezamento de papéis, parecendo ser motivadas e reforçadas pelo prazer associado à capacidade de produzir respostas contingentes e responder contingentemente aos outros; 3 - Brincadeiras simbólicas ou imaginativas: a criança trata os objetos como se fossem outros, podendo atribuir propriedades diferentes das que possuem, ou atribuir a si e aos outros, papéis diferentes dos habituais e/ou criar cenas imaginárias e as representar; 4 - Brincadeiras turbulentas/ agonísticas: envolvem comportamentos de luta, perseguição e fuga, sendo o riso um dos principais aspectos que distinguem a brincadeira de uma luta real; 5 - Jogos de construção: são brincadeiras em que materiais são combinados ou modificados para criar um produto novo; 6 - Brincadeiras e jogos de regras - Há uma ritualização de papéis e representação de cenas pré-determinadas; são, na maioria, jogos competitivos.

Os episódios podem envolver mais de um destes componentes descritos. Para fins de análise, as autoras propõem que seja considerado o critério preponderante de cada episódio, a partir da complexidade da brincadeira, obedecendo a seguinte ordem: regra $>$ simbólica $>$ construção $>$ turbulenta $>$ contingência social $>$ exercício físico. Foi utilizado o critério de Moraes e Carvalho (1994) para a categorização dos temas de faz-de-conta de meninos, adaptado para incluir os temas brincados por meninas. Esses critérios levam em consideração os aspectos descritivos das brincadeiras, possibilitando a classificação dos episódios de faz-de-conta em oito categorias de temas: 1 - Atividades domésticas; 2 - Aventura; 3 - Esportes; 4 - Transportes; 5 - Profissões; 6 - Animais; 7 - Edificações; 8 - Outros: inclui brincadeiras que não se encaixaram nestas categorias e tiveram baixa freqüência.

\section{Resultados e Discussão}

Foram observadas 32 crianças de ambos os sexos: sendo $69 \%$ do sexo masculino e $31 \%$ do sexo feminino. Esse foi o primeiro dado de interesse: a indicação amostral de que existem mais do que o dobro de meninos em relação a meninas nas ruas do povoado, o que por sua vez corrobora a máxima de que os meninos preferem lugares abertos para brincar como a rua, que permite muita movimentação, enquanto meninas preferem ambientes internos e/ou delimitados que possibilitem brincadeiras mais duradouras, escoradas em grandes cenários (Archer, 1992). 
Dentre as meninas observadas, $35 \%$ tinham idade estimada entre dois e seis anos de idade e $65 \%$ entre sete e 12 anos. Este achado contradiz alguns relatos da literatura, que afirmam que é mais comum encontrar meninas mais novas brincando na rua, pois meninas mais velhas costumam se engajar em outras tarefas como ajudar a mãe nos afazeres domésticos, conversar com as amigas etc (Silva, Pontes, Magalhães, Baia da Silva \& Bichara, 2005). Entre as crianças do sexo masculino houve uma distribuição mais homogênea quanto à faixa etária: $42 \%$ tinham entre dois e seis anos e $58 \%$ entre sete e 12 anos.

As ocorrências das brincadeiras foram transformadas em percentuais, primeiramente de forma geral (independente da composição do grupo de brinquedo) e dispostas na Figura 1 , objetivando visualizar as preferências gerais das crianças. Em seguida, calculou-se os percentuais de ocorrência para cada tipo de brincadeira conforme a composição do grupo de brincantes (masculino, feminino e misto), o que foi organizado conforme pode ser visto na Figura 2.

De forma geral, a categoria de brincadeira mais brincada foi a simbólica (49\%) embora meninos e meninas tenham apresentado escores diferenciados representando $57 \%$ das brincadeiras das meninas, $34 \%$ das dos meninos e $66 \%$ das dos grupos mistos.

Essa maior presença de brincadeiras de faz-de-conta em grupos mistos pode ser explicada por este tipo de brincadeira poder incluir mais crianças, além do que a variabilidade de temas, enredos e papéis favorecem a negociação (Black, 1989).

As brincadeiras de regras ocorreram em 14\% dos episódios, seguidas das de exercícios físicos. Entre os meninos houve uma distribuição mais homogênea entre as categorias de brincadeiras, sendo $18 \%$ de episódios de regras, $18 \%$ de brincadeiras turbulentas, $15 \%$ de brincadeiras de construção e $15 \%$ de brincadeiras de exercícios físicos. Esta variabilidade das brincadeiras dos meninos talvez seja favorecida pela quantidade maior de meninos na amostra. Entre as meninas as brincadeiras de regras ocorreram em $29 \%$ dos episódios e $14 \%$ foram de contingência social.
Simbólicas

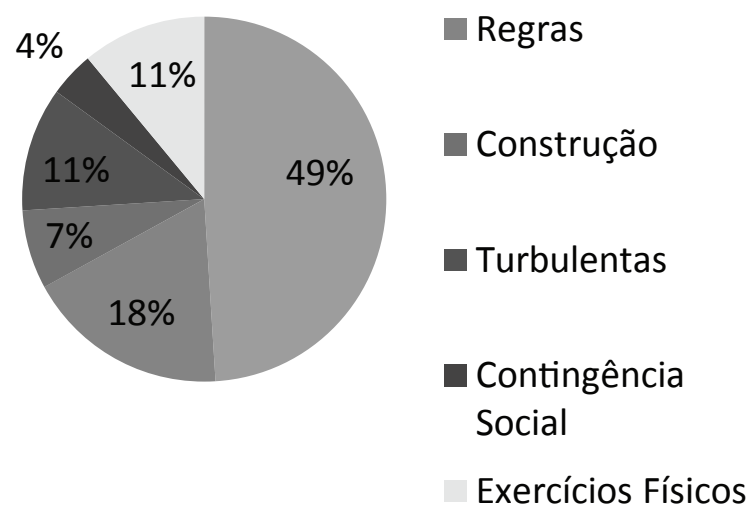

Figura 1. Percentuais de ocorrência para cada tipo de brincadeira.

Constatou-se que entre os meninos houve uma maior diversidade de categorias de brincadeiras e uma distribuição mais homogênea na freqüência de cada uma, reflexo, possivelmente, da presença maior de meninos brincando na rua, com mais liberdade para ocupar espaços mais amplos e afastados de sua casas. Tal como nosso contato geral revelou, levantamos a hipótese de que talvez a predominância de meninos na rua venha da tradição popular de que a rua não é lugar de menina.

As brincadeiras turbulentas ocorreram predominantemente entre meninos, reafirmando o que já é conhecido na literatura. $\mathrm{O}$ brincar de brigar é mais comum entre meninos, consistente com a idéia de que a prática de habilidades de luta é mais importante para meninos. Esta diferença sexual é encontrada através das culturas humanas e em muitas espécies

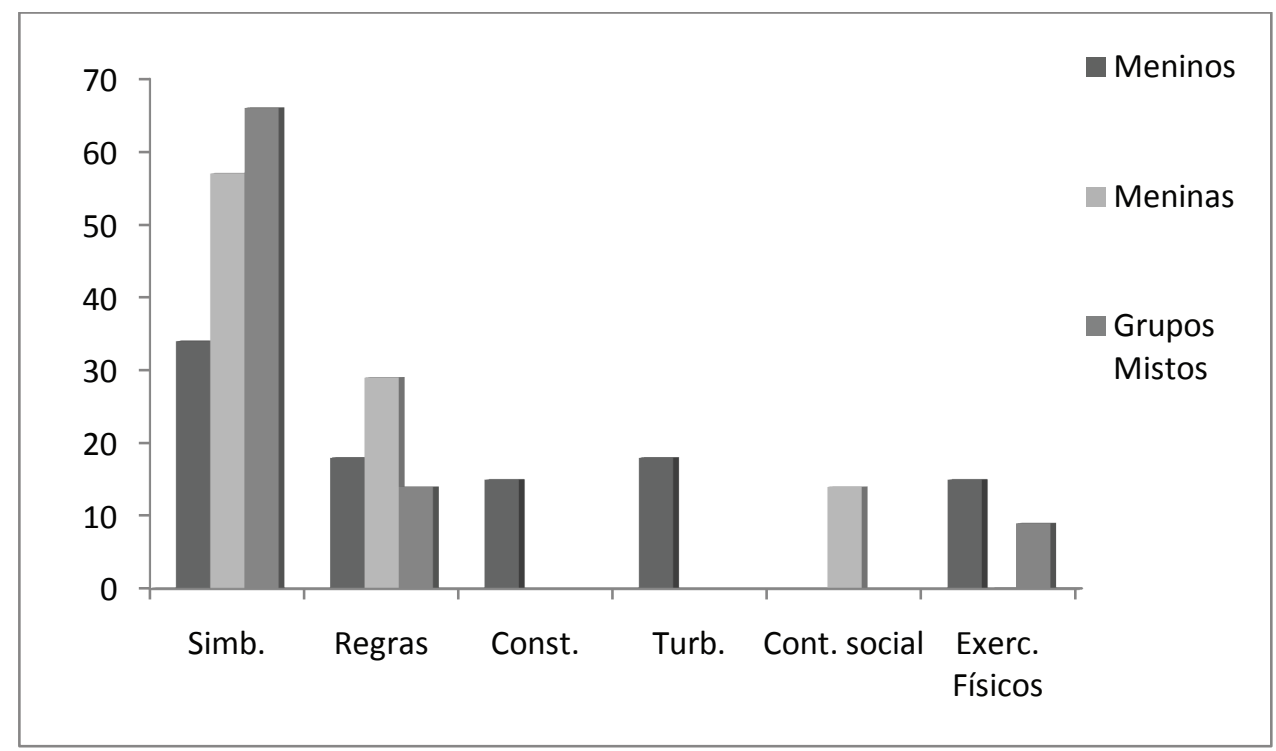

Figura 2. Ocorrência, em percentual, de cada tipo de brincadeira, de acordo com a composição grupal. 
de mamíferos. Num nível próximo, estão relacionados aos hormônios sexuais, notadamente os andrógenos, distalmente, relaciona-se à seleção sexual favorecendo diferentes estratégias reprodutivas em machos e fêmeas (Pellegrini, 2002).

Quando os eventos de brincadeiras são observados em ambientes abertos nos quais as crianças se organizam sem interferência aparente de adultos, uma curiosa questão emerge: a da própria presença numérica de meninos bem maior que a de meninas. Archer (1992) relata que meninos 'preferem' ambientes abertos e brincadeiras que envolvam muita movimentação enquanto as meninas 'preferem' ambientes internos e/ou delimitados e ocupam menos espaços, sendo comum encontrá-las em áreas como vãos sob escadas, interior de armários etc.

Também as brincadeiras que envolvem exercícios físicos como correr e pular e ainda as brincadeiras de regras são pouco freqüentes entre meninas destes ambientes, provavelmente por incluírem elementos considerados masculinos como a movimentação e exibição do corpo em atividades físicas e a permanência na rua por um período de tempo mais extenso, como acontece nos jogos com regras.

\section{A especificidade do faz-de-conta}

Hipotetizamos que as pessoas se conhecem e interagem bastante neste local, hábito estendido para as crianças que ali vivem. Essa convivência mais próxima, adicionada ao fator 'crescer num mesmo ambiente' possibilita que o grupo de brinquedo partilhe idéias comuns que são ponto de partida para o tipo de episódios de brincadeira simbólica encontrados. Essa interação intensa pode favorecer a ocorrência de episódios de faz-de-conta, pois facilita a negociação de papéis, regras, enredo e temas.

Os temas mais freqüentes na brincadeira de faz-de-conta foram transporte para os meninos (86\%) e grupos mistos $(40 \%)$, e atividades domésticas para as meninas (100\%). Esse resultado revela a existência de uma grande estereotipia de gênero na escolha dos temas, principalmente nos grupos segregados, o que condiz com achados anteriores, constantes da literatura, que mostram essa preferência de meninas por temas relacionados com cuidados parentais e outras atividades domésticas e de meninos por atividades envolvendo papéis masculinos.

Esse percentual de crianças brincando de transportes mostra a influência do modo de vida local nas brincadeiras. A partir do contato com moradores do povoado constatamos que muitas crianças têm pais que trabalham com esse transporte e até fazem viagem junto com a família. Mesmo as que não têm esse contato mais próximo, vivem inseridas num ambiente em que este trabalho é uma realidade cotidiana, tanto ao ver essas atividade na sua comunidade, quanto nas conversas entre amigos e vizinho e nas festas da cidade.

Entre as meninas, como visto acima, nos episódios de faz-de-conta registrados os temas estavam relacionados a atividades domésticas, corroborando achados de outras pesquisas (Black, 1989; Gosso \& Otta, 2003; Moraes \& Carvalho, 1994). Dada a notória relação entre a mulher e o trabalho caseiro, acreditamos que este dado reflete a maneira como as meninas percebem o papel feminino na região, re- presentando assim um indício do modo como as brincadeiras de faz-de-conta simultaneamente refletem e preparam para os aspectos elementares da realidade cultural circundante. Vale ressaltar que atividades como cozinhar e cuidar dos filhos não representam práticas predominantemente masculinas em nenhuma sociedade conhecida.

Os estudos realizados com populações tribais como os !Kung e os Hazda mostram que em ambas as crianças brincam de faz-de-conta, mas há variações. O tempo gasto brincando geralmente varia de acordo com custos e benefícios envolvidos no brincar versus forragear e o impacto de cada um destes comportamentos na sua sobrevivência e reprodução. Se a criança pode se engajar de forma segura e eficiente na caça e coleta, como os Hazda, menos tempo é dedicado à brincadeira e mais tempo é gasto na busca e produção de alimentos. No caso dos !Kung, a caça e coleta são relativamente perigosos pelo risco das crianças se perderem e a comida é relativamente disponível para os adultos, assim as crianças têm um longo tempo livre e passam mais tempo brincando (Pellegrini \& Smith, 1998). Seguindo este raciocínio, o faz-de-conta é largamente observado entre crianças do mundo industrializado, dessa forma, a estimativa de gasto de tempo e energia é limitada.

Não observamos influência de temas especificamente extraídos da mídia, mas de representações de conteúdos desta que não lhes são imediatamente acessíveis, cuja caracterização é reflexo direto da imagem passada, conforme diálogo apresentado na Tabela 1.

Tabela 1. Exemplo de diálogo lúdico

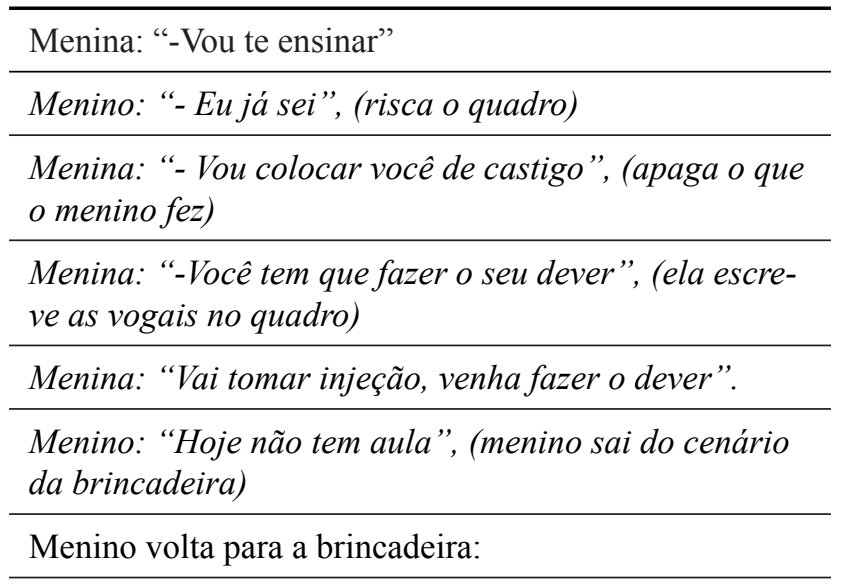

Menino: "Agora sou presidente dos Estados Unidos" (senta-se em postura ereta, olhando a sua volta).

O que estas crianças demonstram neste episódio? A representação que interpretam a partir do que é passado pela mídia: o presidente é alguém visto pela televisão sentado e dando entrevistas, mas a criança entende que é alguém que tem poder, senão não teria sido incorporado a fim de lutar contra uma professora repressiva.

Constatamos que os temas de faz-de-conta das crianças analisadas são muito relacionados ao seu cotidiano e ao mundo adulto, marcados pela ausência de temas francamente fantasiosos, ligados ao imaginário infantil, tais como seres imaginários e superpoderosos, monstros e figuras lendá- 
rias. Por outro lado, sugere uma perspectiva interessante: o ambiente contribui para o incremento da sociabilidade, possibilitado pelo contato próximo com outras crianças e pela liberdade de brincar ambiente de interações livres.

Respaldando esta perspectiva, Black (1989) argumenta que a preferência por temas retirados do dia-a-dia pode dar-se por serem mais propícios ao compartilhamento, pois facilitam a interpretação e negociação, ao passo que Smith (1982) relaciona tal diferencial em criatividade ao fato de que o universo urbano favorece um distanciamento entre adultos e crianças, que conduz estas últimas à exploração de fontes variadas de estímulos (suportes à subjetivização) e interpretação de papéis sociais.

Têm-se constatado em crianças urbanas uma maior presença de conteúdos fantasiosos nas brincadeiras simbólicas, o que Smith (1982) relaciona com o fato de o trabalho dos adultos estar distanciado das crianças pequenas, levando-as a buscar outras fontes de inspiração para a interpretação de papéis sociais, o que é encontrado facilmente em filmes e programas de televisão. Este foi um fato ressaltado nos dados de pesquisas brasileiras em contextos não-urbanos (Gosso \& Otta, 2003; Moraes \& Otta, 2003). Nesses contextos foi pouco encontrada a influência de conteúdos extraídos da televisão e mais episódios onde a fantasia estava ligada à realidade de seu contexto. No estudo com índios Xocó, Bichara (1999) também verifica a existência da mesma relação, encontrando mais temas relacionados com o cotidiano e com um modo de vida rural e ribeirinho.

Foi observado que entre as crianças analisadas as brincadeiras são várias, a despeito da diminuída disponibilidade de brinquedos estruturados. Particularmente, foi encontrada uma grande quantidade de brincadeiras de faz-de-conta, tal sendo um dado contrário à perspectiva de que as crianças pobres exibem capacidade de simbolização diminuída.

Contrariamente a autores que afirmam que brinquedos menos estruturados favorecem a imaginatividade (Haight, Wang, Fung, Williams \& Mintz, 1999), nós apontamos para a importância de um incremento no instrumental lúdico disponível. E contrariamente ao aspecto mais imediato dos dados sobre os efeitos do subdesenvolvimento sobre as crianças, apontamos que o ambiente rural propicia uma experiência de mundo aparentemente mais livre e menos conflituosa, a qual não pode ser relegada a segundo plano quando se trata da concepção de políticas sociais voltadas às crianças.

\section{Considerações Finais}

Muitos ambientes nos quais as crianças de contextos urbanos vivem hoje podem ser considerados seguros e demandam pouco esforço físico quando comparados ao ambiente de adaptabilidade evolutiva. $\mathrm{O}$ ensino formal, a brincadeira supervisionada pelos adultos e o crescente interesse pelas atividades sedentárias como ver televisão, jogar vídeo game e navegar na internet influenciam na quantidade e qualidade da experiência vivida através da brincadeira que, por sua vez traz implicações para o desenvolvimento. O que vemos atualmente é a brincadeira cada vez mais adaptada intencionalmente para o desenvolvimento de certas habilidades na criança, além de atender também a um mercado voltado para a invenção e fabricação de brinquedos.

Isto deveria nos levar a pensar duas vezes antes de modificar o ambiente de brincadeira em prol do alcance de um objetivo (comumente encontrado em escolas) e às custas do brincar.

Uma das características da brincadeira que mais chama a atenção é seu caráter motivador intrínseco. A criança por si só busca e cria a brincadeira, num processo de construção mútua: a criança cria e recria a brincadeira e esta, por sua vez é fator do seu desenvolvimento cognitivo, social e emocional.

O faz-de-conta é influenciado por diversas variáveis sociais. Por exemplo, Bornstein, Haynes, Pascual, Painter e Galperin (1999) constataram que as crianças se engajam com mais freqüência neste tipo de atividade quando há outras crianças disponíveis para brincar. Outro dado importante aponta que quando engajada com a mãe a simbolização é mais complexa. Isto é consistente com a idéia vygotskiana de zona de desenvolvimento proximal. Se a criança interage com um par mais velho ou mais habilidoso que estrutura a situação apropriada às suas capacidades, avança mais rápido em sentido ao aprendizado de novos passatempos, do que se estivesse brincando com colegas de mesma habilidade ou sozinha.

Todas estas questões teóricas discutidas e investigadas sobre o brincar permeiam o âmbito científico voltado ao desenvolvimento infantil, e o que vemos é a confirmação cada vez mais precisa e enfática sobre a importância deste comportamento para a formação de uma criança feliz e saudável, o que nos leva a crer que políticas públicas fundamentadas na ciência do desenvolvimento humano deveriam ser comprometidamente postas em prática.

Adiciona-se a isto que estudar brincadeira e desenvolvimento infantil em geral nos exige derrubar qualquer preconceito ou etnocentrismo que muitas vezes leva a análises parciais e errôneas. A psicologia do desenvolvimento no Brasil vem caminhando em contrapartida a esta postura e os estudos em ambientes específicos estão sendo cada vez mais expandidos, enriquecendo a produção de conhecimento sobre o desenvolvimento de nossas crianças.

Esse direcionamento dado ao estudo da atividade lúdica reflete e evidencia os novos rumos tomados pela pesquisa em psicologia do desenvolvimento, reforçando essa visão emergente que integra comportamento, contexto e cultura.

\section{Referências}

Altmann, J. (1974). Observational study of behaviour: Sampling methods. Behaviour, 49, 227-267.

Archer, J. (1992). Childhood gender roles: Social context and organization. Em H. McGur (Ed.), Childhood social development: contemporary perspectives (pp. 31-61). Hove, U.K.: Lawrence Erlbaum Associates.

Bekoff, M., \& Allen, C. (1998). Intentional communication and social play: how and why animals negotiate and agree to play. Em M. Bekoff, \& J. A. Byers (Eds.), Animal play (pp. 97-114). Cambridge. UK: Cambridge University Press. 
Bekoff, M., \& Byers, J. A. (1998). Play: evolutionary, comparative and ecological perspectives. Cambridge, UK: Cambridge University Press.

Bichara, I. D. (1994). Um estudo etológico da brincadeira de fazde-conta em crianças de três a sete anos. Tese de doutorado, Universidade de São Paulo, São Paulo.

Bichara, I. D. (1999). O faz-de-conta das crianças Xocó e do Mocambo (Porto da Folha/SE). Temas em Psicologia, 7, 57-64.

Bichara, I. D. (2001). Brincadeiras de meninos e meninas: Segregação e estereotipia em episódios de faz-de-conta. Temas em Psicologia, 9, 19-28.

Bjorklund, D. F. (1997). The role of immaturity in human development. Psychological Bulletin, 122, 153-169.

Bjorklund, D. F. (2002). The origins of human nature: evolutionary developmental psychology. Washington, DC: American Psychological.

Black, B. (1989). Interactive pretense: Social and symbolic skill in preschool in play groups. Merril-Palmer Quarterly, 35, 379-397.

Bornstein, M. H., Haynes, M., Pascual, L., Painter, K. M., \& Galperin, C. (1999). Play in two societies: pervasiveness of process, specificity and structure. Child Development, 70, 317-331.

Brougère, G. (1998). A criança e a cultura lúdica. Revista da Faculdade de Educação, 24, 103-116.

Burghardt, G. M. (1999). Conceptions of play and the evolution of animal minds. Evolution and Cognition, 5, 115-123.

Buss, M. D. (2005). The Handbook of Evolutionary Psychology. USA: Wiley.

Carvalho, A. M. A., \& Pontes, F. A. R. (2003). Brincadeira é cultura. Em A. M. A. Carvalho, C. M. C. Magalhães, F. A. R. Pontes, \& I. D. Bichara (Orgs.), Brincadeira e cultura: viajando pelo Brasil que brinca (pp.15-30). São Paulo: Casa do Psicólogo.

Ehrmann, J., Lewis, C., \& Lewis, P. (1968). Homo ludens revisited. Yale French Studies, 41, 31-57.

Eibl-Eibsfeldt, I. (1989). Human Ethology. New York: Aldine de Grutier.

Fagen, R. (1981). Animal play behavior. Oxford: Oxford University Press.

Farver, J. A. M. (1999). Activity setting analysis: a model for examining the role of culture in development. Em A. Göncün (Ed.), Children's engagement in the world: Sociocultural perspectives (pp. 99-127). New York: Cambridge.

Gosso, Y. (2005). Pexe oxemoarai: brincadeiras infantis entre os indios Parakanã. Tese de doutorado. Universidade de São Paulo, São Paulo.

Gosso, Y., \& Otta, E. (2003). Na aldeia Parakanã. Em A. M. A. Carvalho; C. M. C. Magalhães, F. A. R. Pontes, \& I. D. Bichara (Orgs.), Brincadeira e cultura: viajando pelo Brasil que brinca (p.33-76). São Paulo: Casa do Psicólogo.

Gosso, Y., Otta, E., Morais, M. L., Ribeiro, F., \& Bussab, V. S. R. (2005). Play in hunter-gatherer society. Em A. D. Pellegrini, \& P. K. Smith (Eds.), The nature of play: Great apes and humans (pp. 213-254). New York: Guilford.

Göncün, A., Tuermer, U., Jain, J., \& Johnson, D. (1999). Children's play as cultural activity. Em A. Göncün (Org.), Children's engagement in the world, sociocultural perspectives (pp. 148170). New York: Cambridge.
Haight, W. L., Wang, X., Fung, H. H., Williams, K., \& Mintz, J. (1999). Universal, developmental and variable aspects of young children's play: A cross-cultural comparison of pretending at home. Child Development, 70, 1477-1488.

Huizinga, J. (1971/2000). Homo Ludens. São Paulo: Perspectiva.

Johnson, J. E., Christie, J. F., \& Yawkey, T. D. (1999). Play and early childhood development. USA: Longman.

Meaney, M. J., Stewart, J., \& Beatty, W. W. (1985). Sex differences in social play: the socialization of sex roles. Advances in the Study of Behavior, 15, 1-56.

Morais, M. L. S. (2004). Conflitos e (m) brincadeiras infantis: diferenças culturais e de gênero. Tese de doutorado, Universidade de São Paulo, São Paulo.

Moraes, M. S. \& Carvalho, A. M. A. (1994). Faz-de-conta: temas, papéis e regras na brincadeira de crianças de quatro. Boletim de Psicologia, 100/101, 21-30.

Moraes, M. S. \& Otta, E. (2003). Entre a serra e o mar. Em A. M. A. Carvalho, C. M. C. Magalhães, F. A. R. Pontes, \& I. D. Bichara (Orgs.), Brincadeira e cultura: viajando pelo Brasil que brinca (pp.127-156). São Paulo: Casa do Psicólogo.

Oke, M., Khattar, A., Pant, A. K. P. \& Saraswathi, T. S. (1999). A profile of children's play in urban India. Childhood, 6, 207-219.

Parker, S. T. (1984). Playing for keeps: An evolutionary perspective on human games. Em P. K. Smith (Ed.), Play in animals and humans (pp. 271-293). Oxford, UK: Basil Blackwell.

Pellegrini, A. D. (2002). Rough-and-toumble play from childhood through adolescence: development and possible functions. Em P. K. Smith, \& C. H. Hart (Eds.), Handbook of childhood social development (pp. 438-453). Oxford, England: Blackwell.

Pellegrini, A. D., \& Bjorklund, D. F. (2004). The ontogeny and phylogeny of children's object and fantasy play. Human Nature, 15(1), 23-43.

Pellegrini, A. D., \& Smith, P. K. (1998). The development of play during childhood: forms and possible functions. Child psychology \& psychiatr, 3 (2), 51-57.

Piaget, J. (1971). A formação do símbolo na criança. Rio de Janeiro: Zahar.

Power, T. G. (2000). Play and exploration in children and animals. Mahwah, NJ: Lawrence Erlbaum Associates.

Ribeiro, F. J. L., Bussab, V. S. R., \& Otta, E. (2005). Brincadeira e autocuidado: as funções da infância [Resumo]. Em Sociedade Brasileira de Psicologia do Desenvolvimento (Org.), Anais do $V$ Congresso Brasileiro de Psicologia do Desenvolvimento (p. 27). São Paulo: SBPD.

Rosenberg, A. (1990). Is there an evolutionary biology of play? Em M. Bekoff, \& D. Jamieson (Eds.), Interpretation and explanation in the study of animal behavior, Vol. 1: Interpretation, intentionality, and communication (pp. 180-196). Boulder, CO: Westview Press.

Seild de Moura, M. L. (2006). Bases para uma psicologia do desenvolvimento sociocultural e evolucionista. Em F. A. R. Pontes, C. M. C. Magalhães, R. C. S. Brito, \& W. L. B. Martin (Orgs.), Temas pertinentes à construção da psicologia contemporânea (pp.15-42). Pará: EDUPA.

Silva, L. I. da C., Pontes, F. A. R., Magalhães, C. M. C., Baia da Silva, S. D., \& Bichara, I. D. (2005). Diferenças de gênero(s) nos grupos de brincadeira na rua: elementos para pensar a hipótese de aproximação cultural. Psicologia: Reflexão $e$ Critica, 19, 114-121. 
Spinka, M., Newberry, R. C., \& Bekoff, M., (2001). Mammalian play: training for the unexpected. The quarterly review of biology, 2, 141-168.

Smith, P. K. (1982). Does play matter? Functional and evolutionary aspects of animal and human play. Behavioral and Brain Science, 5, 139-184.

Smith, P. K., Cowie, H., \& Blades, M. (1998). Understanding Children's Development. Oxford: Blackwell Publishers.

Smith, P. K. \& Dosdsworth, C. (1978). Social class differences in the fantasy play of preschool children. The Journal of Genetic Psychology, 133, 183-190.

Sutton-Smith, B. (1986). Toys as culture. New York: Gardner Press.

Taylor, M., \& Carlson, M. S. (1997). The Relation between individual differences in fantasy and theory of mind. Child Development, 68, 436-455.
Tomasello, M., \& Call, J. (1997). Primate cognition. New York: Oxford University Press.

Vygotsky, L. (2000). A formação social da mente. São Paulo: Martins Fontes.

Yamamoto, M. E., \& Carvalho, A. M. A. (2002). Brincar para que? Uma abordagem etológica ao estudo da brincadeira. Estudos de Psicologia, 10, 163-164.

Recebido em 16.09.08

Primeira decisão editorial em 27.07.09

Versão final em 18.09.10

Aceito em 14.10.10 